\title{
Design and operational strategies for good Indoor Air Quality in low-energy dwellings: performance evaluation of two apartment blocks in East London, UK
}

\author{
Esfand Burman*, Clive Shrubsole, Samuel Stamp, Dejan Mumovic, Michael Davies \\ Institute for Environmental Design and Engineering, University College London (UCL), \\ Central House, 14 Upper Woburn Place, London, WC1H 0NN, UK \\ *Corresponding email: esfand.burman@ucl.ac.uk
}

\begin{abstract}
To achieve stringent energy objectives, new dwellings are subject to energy conservation measures including low air permeability and high levels of insulation. Mechanical Ventilation with Heat Recovery (MVHR) can be used to control the balance between energy efficiency and Indoor Air Quality (IAQ) in these buildings. This paper evaluates the effectiveness of the design and operational strategies adopted in a new development comprising two apartment blocks in East London. The findings point to significant gaps in operational energy use compared against design projections, and high concentrations in benzene and formaldehyde three years after construction. It is suggested that a combination of internal source control measures at design stage and building fine-tuning in early stages of post-occupancy is necessary to close the performance gap in energy and IAQ.
\end{abstract}

\section{KEYWORDS}

Low-energy dwellings, IAQ, MVHR, Performance gap

\section{INTRODUCTION}

In pursuing energy objectives such as the nearly zero-energy target in Europe, the existing standards for building air tightness and fabric heat loss are reaching their technical and economic limits. There is thus a risk that the focus may be shifting to save energy by reducing ventilation demand with potential adverse impacts on health and wellbeing. Annex 68 of the Energy in Buildings and Communities Programme of the International Energy Agency (IEA EBC Annex 68) aims to address this issue by finding design solutions and operational strategies that help achieve low energy and good IAQ in new dwellings. A review of empirical evidence carried out as part of the on-going activities in IEA EBC Annex 68 found that concentrations of pollutants such as toluene, ethylbenzene, trichloroethylene and styrene in new low energy dwellings were up to 10 times higher than in old dwellings (Salis, et al., 2017). Another driver for a focus on IAQ is heavy traffic and high outdoor pollution (e.g. micro particles and $\mathrm{NO}_{2}$ ) in cities such as London and Beijing (Walton, et al., 2015).

The work presented in this paper is part of a wider research programme entitled 'Total Operational Performance of Low Carbon Buildings in China and the UK (TOP)', which covers the energy and environmental performance of a large cross section of non-domestic buildings and apartment blocks. The aim of this paper is to evaluate the Energy and IAQ performance of a new residential development. The specific objectives are to: 1) compare operational energy against design projections, 2) monitor the concentration level of major outdoor and indoor driven air-borne pollutants, and 3) identify the improvement opportunities to close the performance gaps in energy and IAQ in the context of the case study, and more generally suggest improvements for future projects. 


\section{OVERVIEW OF THE CASE STUDY}

To investigate IAQ in low energy residential buildings, two recently built apartment blocks constructed as part of a regeneration scheme in East London were selected as a case study.

Apartment blocks A and B were completed in December 2014 and January 2015 respectively. Block A is a 13-storey building; Block B has 9 floors. They are located next to each other and close to two main roads in the London Borough of Tower Hamlets in East London. There are 97 flats and maisonettes (two-storey apartments) in these blocks. Building fabric U values are around $40 \%$ better than the limits prescribed by the 2013 edition of the Building Regulations. The buildings were also designed with target air permeability of $2-3 \mathrm{~m} / \mathrm{hr} . / \mathrm{m}^{2}$ at $50 \mathrm{~Pa}$ pressure difference which is significantly lower than $10 \mathrm{~m} 3 / \mathrm{hr} . / \mathrm{m}^{2}$ limit set out in the Building Regulations (HM Government, 213). Consequently, mechanical ventilation with heat recovery (MVHR) was specified to ensure adequate background ventilation is provided to these apartments. Heating is provided by a community heating scheme that is currently gas fired with provisions for integration of a combined heat and power (CHP) plant in future. There is no mechanical cooling. Table 1 provides background information about the sample apartments included in this study. The air permeabilities reported are based on pressure test results carried out on these apartments after building completion.

Table 1. Background information about sample apartments

\begin{tabular}{llcllccc}
\hline Dwelling & Type & $\begin{array}{l}\text { Gross } \\
\text { Floor } \\
\text { Area }\left(\mathrm{m}^{2}\right)\end{array}$ & $\begin{array}{l}\text { Floor } \\
\text { level }\end{array}$ & Orientation & $\begin{array}{l}\text { Bedroom } \\
\text { no. }\end{array}$ & $\begin{array}{l}\text { Occupant } \\
\text { no. } \\
(\text { steady } \\
\text { mode })\end{array}$ & $\begin{array}{l}\text { Air } \\
\text { tightness } \\
\left(\mathrm{m}^{3} / \mathrm{hr}^{2} \mathrm{~m}^{2}\right. \\
\text { @ 50 Pa })\end{array}$ \\
\hline Apt. 1 & Flat & 100 & $\begin{array}{l}\text { Block A, South/West } \\
7^{\text {th }} \text { floor }\end{array}$ & 3 & 3 & 3.3 \\
\hline Apt. 2 & Flat & 100 & $\begin{array}{l}\text { Block A, South/West } \\
8^{\text {th }} \text { floor }\end{array}$ & 3 & 5 & 2.2 \\
\hline Apt. 3 & Flat & 100 & $\begin{array}{l}\text { Block A, North/West } \\
\text { 9th floor }\end{array}$ & 3 & 5 & 2.0 \\
\hline Apt. 4 & Maisonette & 127 & $\begin{array}{l}\text { Block B, South/East } \\
\text { Ground } \\
\text { floor }\end{array}$ & 5 & 7 & 3.8 \\
\hline Apt. 5 & Maisonette & 106 & $\begin{array}{l}\text { Block B, East } \\
8^{\text {th }} \text { floor }\end{array}$ & 3 & 4 & 2.9 \\
\hline
\end{tabular}

METHOD

The following activities were planned with relevant methods adopted:

1) Energy monitoring: A review of the annual energy performance of the apartments that were fully occupied during the monitoring period and had reliable energy data was carried out. Heating demands of these apartments were compared against the projections made in the respective Energy Performance Certificates produced after completion in accordance with the Standard Assessment Procedure (BRE, 2012). Available data for the community heating scheme serving the blocks were sourced from its Energy Service Company (ESCO) to evaluate the supply side. Electricity use of five sample apartments sourced from the electrical meters were also compared against the benchmarks.

2) Active monitoring of IAQ: Five sample apartments were selected for detailed analysis of IAQ to meet the minimum sampling requirement of $5 \%$ of zones in large buildings in BS EN 15251 (BSI, 2007). IAQ sensors were installed to measure the concentration levels of $\mathrm{CO}_{2}, \mathrm{PM}_{2.5}$ and $\mathrm{NO}_{2}$ in living rooms and kitchens of the apartments during typical weeks 
in the heating season (February-March 2018) with 5-minute frequency. ${ }^{1} \mathrm{CO}_{2}$ levels were also monitored in one bedroom. $\mathrm{CO}_{2}$ concentrations are often used as a proxy for IAQ in the UK construction sector. $\mathrm{PM}_{2.5}$ and $\mathrm{NO}_{2}$ were identified as pollutants with risk of high concentration in new low energy buildings in the IEA EBC Annex 68 programme with significant health impacts, and are also of great interest in London due to major outdoor sources for these pollutants. Concentrations of these pollutants were compared against the recommended limits provided in BS EN 15251 and WHO guidelines (WHO, 2006).

3) Passive Sampling for IAQ: the diffusive sampling method, in accordance with ISO 16017, was used to measure the average concentrations of volatile organic compounds (VOCs) with risk of concentrations higher than long-term/chronic exposure limit values (ELVs) in new low energy dwellings (Salis, et al., 2017). Concentration levels of benzene, formaldehyde, trichloroethylene, styrene, naphthalene, toluene, and tetrachloroethylene were measured in living room, kitchen and one bedroom of the sample apartments during the same weeks active monitoring took place. Passive tubes and absorbent pads were also installed outdoors to identify the indoor/outdoor trends and sources.

Finally, to give context to IAQ monitoring results, a perfluorocarbon tracer (PFT) gas method (Persily, 2016) was used to infer the average air exchange rates in the monitored zones of the sample apartment.

\section{RESULTS}

Energy: Figure 1 compares the actual heating demand of 40 apartments in the case study against the design projections. Actual heating demand in 30 apartments is higher than expected and in the worst case is around three times more than the design performance. Figure 1 also shows a snapshot of a thermographic survey of the case study which did not reveal any significant defects or thermal bridges within the external envelope. These observations, combined with the variation in heating demand across different apartments, suggests the overall increase in heating demand is predominantly driven by occupant behaviour (e.g. heating set points and heating schedules), and is reminiscent of the rebound effect seen in new dwellings built to meet energy efficiency requirements (Kelly, 2011).

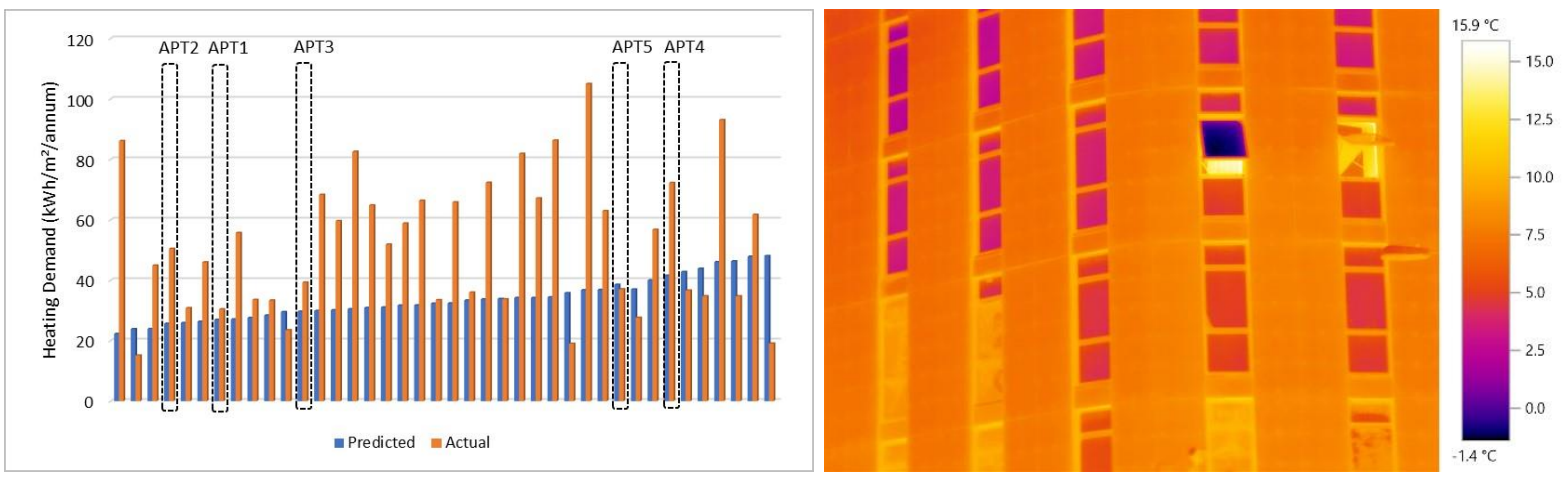

Figure 1. Actual vs. design heating demand, and external envelope thermographic survey

The annual gas use data and the data for delivered heat to the apartments released by the ESCO running the community heating scheme show an average annual heating efficiency of $50 \%$, significantly lower than the design specification of $87 \%$. This exacerbates the performance gap between actual operation and design intent.

\footnotetext{
${ }^{1}$ Measurement accuracies: $\mathrm{CO}_{2}: \pm 50 \mathrm{ppm}, \mathrm{PM}_{2.5}: 0.84$ coincidence probability at $10^{6}$ particles $/ \mathrm{L} ; 0.24$ coincidence probability at 500 particles $/ \mathrm{L}, \mathrm{NO}_{2}:< \pm 0.5 \mathrm{ppm}$
} 
Annual electricity use of all sample dwelling is higher than design intent with a maximum 53\% deviation in Apartment 3.

Active monitoring of IAQ: Figure 2 shows the boxplots for indoor concentration levels of $\mathrm{CO}_{2}$, and indoor and outdoor concentrations of $\mathrm{PM}_{2.5}$, and $\mathrm{NO}_{2}{ }^{2}$
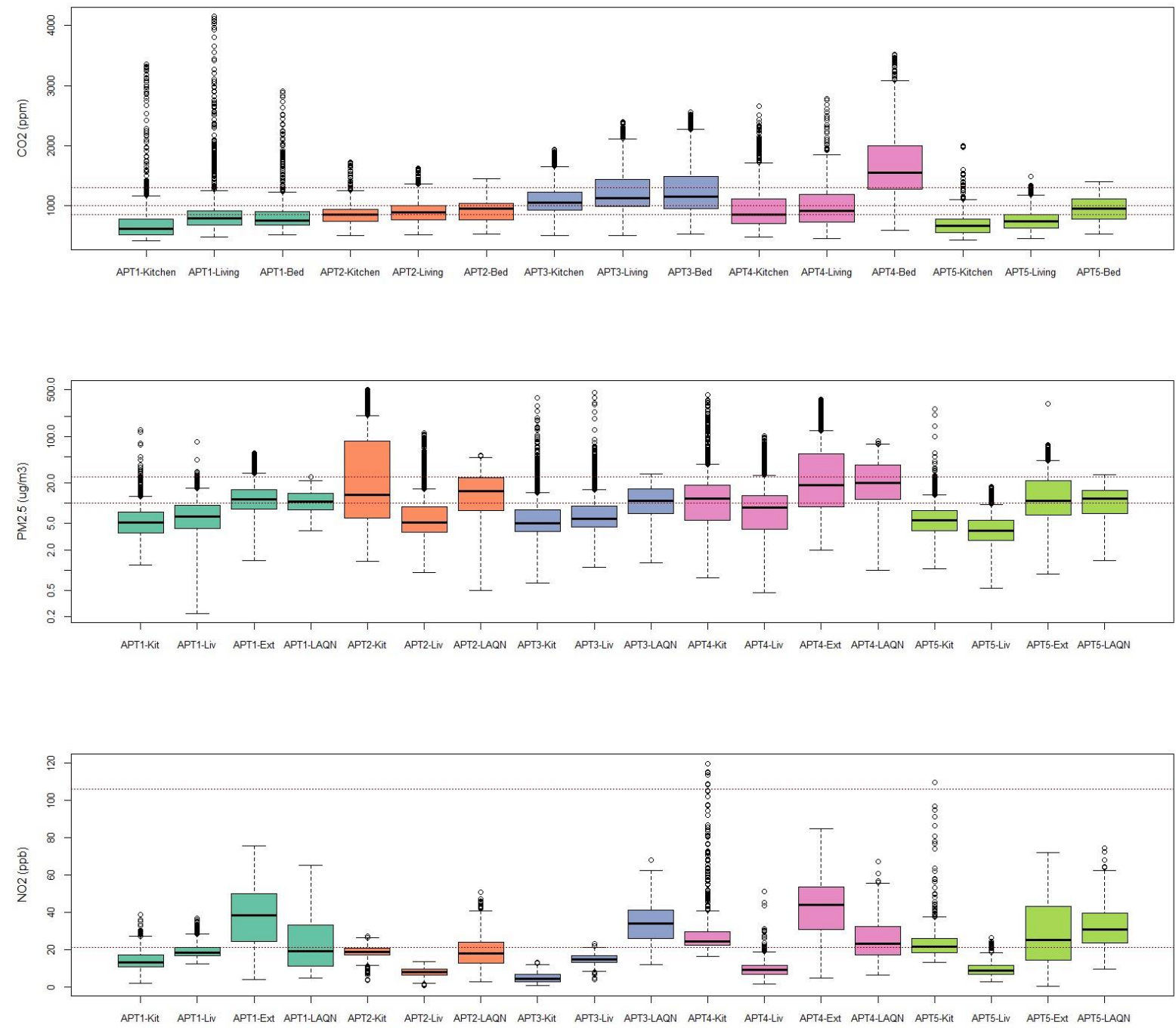

Figure 2. Concentrations of $\mathrm{CO}_{2}, \mathrm{PM}_{2.5}$, and $\mathrm{NO}_{2}$ during typical weeks in heating season

The dotted horizontal lines on the $\mathrm{CO}_{2}$ graph represent 350, 500, and $800 \mathrm{ppm}$ above external $\mathrm{CO}_{2}$ concentrations in keeping with the classification provided in BS EN 15251. Apartments 3 and 4 show $\mathrm{CO}_{2}$ concentration levels above the other apartments and the most lenient guideline limit, which could be indicative of inadequate ventilation. The guideline limits for $\mathrm{PM}_{2.5}$ are the WHO annual and daily means of $10 \mu \mathrm{g} / \mathrm{m}^{3}$ and $25 \mu \mathrm{g} / \mathrm{m}^{3}$ respectively. It is notable that the outdoor $\mathrm{PM}_{2.5}$ levels are often higher than WHO guideline for annual mean. However, indoor concentrations in most spaces are kept below the guideline limit most of the time, which could be indicative of the effectiveness of the air filtration installed in the MVHR system. Whilst outdoor levels are again often higher than the WHO annual mean $\left(40 \mu \mathrm{g} / \mathrm{m}^{3}\right.$, $21 \mathrm{ppb}$ ), indoor $\mathrm{NO}_{2}$ levels are generally lower than this limit, except in the kitchens of Apartments 4 and 5. Indoor $\mathrm{NO}_{2}$ levels are generally well below the WHO hourly guideline

\footnotetext{
${ }^{2}$ Ext: external air quality kit installed onsite, LAQN: closest weather station to the site
} 
limit of $200 \mu \mathrm{g} / \mathrm{m}^{3}$ (105 ppb). In addition to the effect of outdoor sources, $\mathrm{PM}_{2.5}$ and $\mathrm{NO}_{2}$ levels in apartments could be increased by internal sources especially in the kitchens.

Passive Sampling for IAQ: Table 2 reports the results of passive sampling for Apartments 3 and 4. These apartments were selected for reporting in this paper as the active monitoring results pointed to potential ventilation issues in these apartments. Furthermore, this selection allows a cross comparison of the dispersion of pollutants in the lowest (ground floor) and highest ( $9^{\text {th }}$ floor) height in the sample and between different building orientations.

Table 2. Passive sampling results for Apartments 3 and 4 (typical weeks in heating season)

\begin{tabular}{|c|c|c|c|c|c|c|c|}
\hline \multirow{2}{*}{$\begin{array}{l}\text { VOC concentration } \\
\left(\mu \mathrm{g} / \mathrm{m}^{3}\right) \\
\& \\
\text { Air Change rates } \\
\text { per Hour for each } \\
\text { zone }\end{array}$} & \multicolumn{3}{|c|}{ APT. 3 (Block A, 9th Floor) } & \multicolumn{3}{|c|}{$\begin{array}{c}\text { APT. } 4 \text { (Block B, Ground } \\
\text { Floor) }\end{array}$} & \multirow{2}{*}{$\begin{array}{l}\text { IEA } \\
\text { EBC } \\
\text { Annex } \\
68 \text { Long } \\
\text { Term } \\
\text { ELV }\end{array}$} \\
\hline & $\begin{array}{l}\text { Living } \\
\text { room }\end{array}$ & Kitchen & $\begin{array}{c}\text { Sample } \\
\text { bedroom }\end{array}$ & $\begin{array}{l}\text { Living } \\
\text { room }\end{array}$ & Kitchen & $\begin{array}{l}\text { Sample } \\
\text { bedroom }\end{array}$ & \\
\hline Benzene & 1.3 & 1.0 & 1.2 & 1.5 & 2.1 & 1.6 & 0.2 \\
\hline Formaldehyde & 29.25 & 26.87 & 29.53 & 21.23 & 31.35 & 27.44 & 9 \\
\hline Trichloroethylene & $<0.5$ & $<0.5$ & $<0.5$ & $<0.5$ & $<0.5$ & $<0.5$ & 2 \\
\hline Styrene & 1.5 & 2.2 & 3.0 & 0.8 & 0.7 & 1.7 & 30 \\
\hline Naphthalene & 5.4 & 5.4 & 5.0 & 0.9 & 0.9 & 1.3 & 2 \\
\hline Toluene & 2.7 & 2.9 & 3.1 & 2.2 & 2.6 & 2.4 & 250 \\
\hline Tetrachloroethylene & 0.6 & $<0.6$ & $<0.6$ & 1.5 & 1.2 & 1.8 & 100 \\
\hline $\begin{array}{l}\text { ACH (PFT } \\
\text { measurements) }\end{array}$ & 0.50 & 0.52 & 0.76 & 1.02 & 1.14 & 0.6 & $\mathrm{n} / \mathrm{a}$ \\
\hline
\end{tabular}

The VOCs with concentration levels higher than the recommended long-term ELVs are highlighted in bold. While high concentrations of Naphthalene could be a specific problem in Apartment 3 related to occupant behaviour (e.g. smoking or use of chemical insecticides/pest control), concentrations of Benzene and Formaldehyde in both apartments are significantly higher than the respective ELVs. Measurement of outdoor concentrations confirm benzene is driven by outdoor sources, whereas formaldehyde levels are driven by internal sources.

\section{DISCUSSION}

The outcomes of this study point to the challenge of achieving a 'low energy' building in practice. People's expectation of comfort in new dwellings may be different than their previous older accommodation. This case study represented a social housing scheme. An appropriate system of incentives and effective behavioural strategies may be developed in parallel with design processes and implemented post-occupancy to address potential rebound effects. From a supply point of view, the existing operational efficiency of the community heating scheme is a key driver of the performance gap. This is however not a unique case. Detailed studies of community heating schemes have found operational efficiencies as low as $37 \%$ (Wingfield, et al., 2013). The existing plant room in the case study is currently not running at full capacity, as the second phase of the development has not yet been completed and part load performance compromises efficiency. Distribution losses are also a major issue and significantly higher than the default factor of 5\% assumed for new developments in the Standard Assessment Procedure (BRE, 2012). Better understanding of inefficiencies in energy generation and distribution can help narrow the energy performance gap. If the operational issues are addressed, a community heating scheme provides ample opportunities for further improvements including decarbonisation by integrating CHP plant with other technologies. Air filtration in the installed MVHR units appear to be effective. The ventilation rates inferred from PFT measurements are also generally consistent with the minimum ventilation 
requirements set out in the UK Building Regulations (HM Government, 2010), although the MVHR system is only partially responsible for air exchange, and other factors such as natural ventilation (via window opening) are also effective. Enhanced ventilation beyond the regulatory requirements by adjusting the fan speed in the MVHR to its boost or maximum flow rate can help reduce formaldehyde levels, although this can also increase the concentrations of outdoor driven pollutants such as benzene as well as energy use. A trade-off based on an assessment of health impact of these pollutants may inform the ventilation strategy. However, a more fundamental solution in future projects is to improve source control of materials used in the building and furniture to keep formaldehyde levels below the limits. The fact that after three years of building handover formaldehyde levels are higher than three times the chronic ELV points to significant IAQ issues and potential health impacts. This problem can be addressed by a combination of source control and enhanced/boost ventilation in the early stages of post-occupancy with seasonal commissioning to reduce fan speed after the off-gassing period and when measurements confirm concentrations of formaldehyde and other critical pollutants are acceptable.

\section{CONCLUSIONS}

This study uncovered significant gaps in energy performance and concentration levels of benzene and formaldehyde in dwellings more than 3 years after construction. The gap between actual building performance and design intents is currently not adequately addressed in energy efficiency policies. The intricate relation between energy efficiency requirements and IAQ may also lead to unintended consequences for IAQ where sources of pollution are not effectively controlled and ventilation is not adequate. Building performance evaluation and fine-tuning in the early stages of post-occupancy should be an integral part of building procurement process to ensure low energy and good levels of IAQ are delivered in practice.

\section{ACKNOWLEDGEMENT}

The authors wish to thank building occupants for their support and participation in research. This research was funded by the EPSRC ('TOP' project, Grant Code: EP/N009703/1).

\section{REFERENCES}

BRE, 2012. The Government's Standard Assessment Procedure for Energy Rating of Dwellings, Watford: BRE.

BSI, 2007. BS EN 15251:2007, Indoor Environmental Input Parameters for Design and Assessment of Energy Performance of Buildings Addressing Indoor Air Quality, Thermal Environment, Lighting and Acoustics, London: BSI.

HM Government, 2010. Approved Document Part F, Means of ventilation, s.1.: NBS.

Kelly, S., 2011. Do homes that are more energy efficient consume less energy?: A structural equation model of the English residential sector. Energy, Volume 36, pp. 5610-5620.

Persily, A., 2016. Field measurement of ventilation rates. Indoor Air, 26(1), pp. 97-111.

Salis, L. C. R., Abadie, M., Wargocki, P. \& Rode, C., 2017. Towards the definition of indicators for assessment of indoor air quality and energy performance in low-energy residential buildings. Energy and Buildings, Volume 152, pp. 492-502.

Walton, H. et al., 2015. Understanding Health Impacts of Air Pollution in London, London: King's College London.

WHO, 2006. WHO Air quality guidelines for particulate matter, ozone, nitrogen dioxide and sulfur dioxide, Geneva: The World Health Organization (WHO).

Wingfield, J. et al., 2013. Centenary Quay Fabric and District Heating Performance Study, London: Innovate UK Building Performance Evaluation programme. 